\title{
A Microeconomic System-Wide Approach to the Estimation of the Demand for Money
}

\author{
Salam K. Fayyad
}

STABLE demand-for-money relationship is a necessary condition for the viability of a monetary policy based on the use of monetary aggregates as intermediate policy targets. In recent years, standard money-demand formulations have exhibited large shifts that remain largely unexplained loday despite extensive research efforts devoted to detemining the reasons for these shifts.

This paper presents an altemative to the standard single-equation method of estimating the demand for money. The altemative, called the microeconomic system-wide approach to demand analysis, differs in several fundamental ways from the usual money demand specification. The purpose of this article is to show how the system-wide approach can be applied to estimating the demand for money. The results indicate that in-sample predictions made using this approach closely track the actual data over the 1969-85 period.

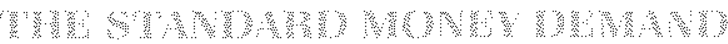

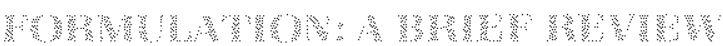

Over the past three decades, most demand-formoney studies have employed similar specifications. Typically they use income (as a transaction variable and one or more (typically two) interest rates (to cap-

Salam K. Fayyad is an assistant professor at Yarmouk University (Jordan) and a former visiting scholar at the Federal Reserve Bank of St. Louis. The author is intellectually indebted to his teacher, William A. Barnett. Laura A. Prives provided research assistance. ture the effect of the opportunity cost of holding moneyl as explanatory variables; the dependent variable is generally the stock of real M1 balances.

The wide acceptance of the standard money demand specification is understandable. It embodies a proposition, which, since Keynes' General Theory, has constituted a key tenet of the received wisdom on the demand for money: the desire to hold money balances is directly related to the need to conduct transactions and inversely related to the opportunity cost of holding money balances. In addition, it performed remarkably well in a statistical sense. The coefficients of the explanatory variables had "sensible" signs and magnitudes, and the estimated model fit the data very well.

The disquietude accompanying Goldfeld's (1976) discovery that his standard formulation of the demand-for-money function began in 1973 to systematically overpredict the real money balances underscores the importance that has been altached to the stability, and hence predictability, of the demand for money, It is not surprising that the reported shift in Goldfeld's specification, or what, after 1976 , became generally known as the "case of the missing money," instigated a seemingly tireless search for a verifiable explanation of what happened.'

A review of the vast liferature devoted to finding the reasons for the shift in money demand reveals that these studies are largely unsuccessful in accounting

\footnotetext{
A recent study suggests that the demand-for-money function has undergone shifts in the periods III/1962, IV/1973, IV/1979, and $U$
} 1980. See Mizrach and Santomero (1986). 
for it. For example, Laidler has commented that:

The first thing to be said . . is whatever else they do they do not rescue the demand for $M$, function from the suspicion of instability... IThe often unsatisfac. tory resuls ... indicate that further work is required. rather than that the line of inquiry that they represent should be abandoned.

The inconclusiveness of the evidence on what caused the standand money-demand specification to shift in 1973 can be viewed as an indication that examining alternative approaches to the demand-formonev formulation might be usefut. The alternative offered here is derived from a microeconomic system-wide approach to demand analysis.

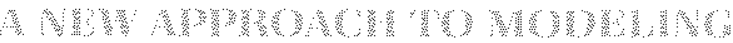

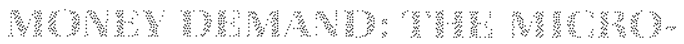

The basic premise which underlies any micho theoretic approach to consumer demand analysis is that the consume maximizes a neoclassical utility funetion subject to a budget constraint." A model consistent with both the principles of microeconomic theory and aggregation theory yields specific behavioral implications which can be tested using available data aggregated over goods and consumers. (Some criticisms of including money in this approach appear on page 24.

This study uses a neoclassical utility function defined over five expenditure categories, two of which are presumed to capture the "monetary services" in the U.S. economy. By restricting the analysis to five expenditure categories, this study assumes the existence of a macro utility function that is weakly separable in these categories. ${ }^{+}$

The solution to the consumer choice problem when the utility function is defined over five goods is a system of fve demand equations. In each equation, the quantity demanded of a specifc good is expressed as a function of the total amount available for spend-

'See Judd and Scadding (1982), p. 1014.

${ }^{3} \mathrm{~A}$ neoclassical utility function is one that is continuously twice differentiable and quasiconcave with positive marginal utility everywhere.

${ }^{4}$ A neoclassical utility function is weakly separable in a block of goods if and only if the marginal rate of substitution between any two goods inside the block is independent of consumption outside that block. White this separability assumption may seem overly restrictive, it is actually less restrictive than that maintained by studies in which money is considered to be the sole argument in the utitity function. See, for example, Ewis and Fsher (1984). ing on all five goods, and in the general casel of their prices. Naturally, the exact specification of these dem mand equations will depend on the specific form of the utility function chosen. This study, howeves, uses a general demand system consistent with the maximization of an arbitrary neoclassical utility function. Thus, white the system is subject to all the restrictions that economic theory implies, the results are invariant to the functional form of the utility function being maximized. This choice avoids the loss of generality which may result if a particular functional form is specified and pemits testing of hypotheses about the structure of the utility function itself.

The microeconomic system-wide approach to demand analysis deals with the allocation of total spending among the individual goods considered. Thus, for the specific set of goods chosen, the explanatory variables in the demand system are the amount available for spending and the prices of these goods. This approach provides a comvenient means for acquiring detailed information about utility-based attributes of goods; this information is readily available by inspecting the signs land, of course, the statistical and economic significance) of estimated income, own- and cross-price parameters.

The demand model used in this study, the absolute price version of the Rotterdam model, was chosen primarily because the theoretical restrictions are readily expressed in tems of the model's parameters. This makes it relatively easy to impose and to test the validity of these restrictions." Another attractive fea ture of the Rotterdam model is that it can be used to provide predictions of the value (budget) shares of the goods included in the analysis. These predictions can be used to compute measures of informational inaccuracies useful in assessing the performance of the demand system as a whole and the individual demand equations as well.

The monetary variables used are the real flow of monetary services provided by various monetary assets, not the simple sum of the real stocks of monetary aggregates generally used in standard money-demand analysis. A measure of the monetary-service flows was obtained by evaluating the stocks of monetary assets at their comesponding user-cost prices (see the discussion of the data below. The user-cost price of each monetary asset is the difference between the interest

\footnotetext{
in the aggregated-over-consumers verston of the model derved by Bamet (1979), the macro parameters are subject to the same restrictions as their micro counterpatis. (See lootnote 9 )
} 


\section{Can Money Be Included in a Microeconomic System-Wide Demand Model?}

The applicability of the theoretical restrictions in the general case of demand for money and goods has been questioned. In fact, if, as in the Samuelsonian tradition, the utility-based analysis of the demand for money is handled by putting money and prices in the utility function, then, by the strong results produced by Samuelson and Sato (1984), the restrictions in question, as they pertain to the demand for goods, are simply unattainable. While potentially disquieting, the Samuelson-Sato results are not unqualifiedly binding. Indeed, these results are founded in the view, long espoused by Samuelson, that, in connection with the inclusion of money in the preference structures, money is wanted solely for the purposes of facilitating transactions. As Samuelson (1983), p. 117, states:

In this connection, I have reference to none of the tenuous concepts of money, as a numeraire commodity, or as a composite commodity, but to money proper, the distinguishing features of which are its indirect usefuness, not for its own sake but for what it can buy, its acceptability, its not being "used up" by use, etc, etc.

This is the rationale behind Samuelson's inclusion of prices and money in the utility function specified to be homogeneous of degree zero in both money and prices. It is precisely this formulation to which the Samuekon-Sato results pertain.

One could argue that Samuelson's view of what money is wanted for is unduly restrictive. In fact, of the assets currently regarded as potential sources of monetary services in the U.S, economy (see table 1), only a few are "generally acceptable in exchange." Furthermore, the supposition, based on Samuelson's view, that money cannot properly be treated like other commodities can also be ques-

In this study, the Federal Reserve's defintion of monetary assets was taken as given. The use of the Fed's definitions does not mean that the list of assets which appears in table 1 includes all assets that provide monetary services in the U.S. economy or, for that matter, that all assets included in the list provide such services. tioned. Households consume the services provided by various expenditure categories ostensibly because of the utility they derive from these expenditure categories: in general, little, if any, effort is directed toward deciphering the nature of the utility involved in those cases. By the same token, it can be maintained that money is held because of the utility it provides, without having to speculate as to whether that utility derives from money's "general acceptability in exchange," the serenity its holders experience by holding it, or from any other knowable or even unknowable attribute." Indeed, if money can be treated like other goods, then it can be included in the utility function in precisely the same manner as any other good. In that case, the Samuelson-Sato results would not apply, and one could thus impose or test for any of the restrictions implied by economic theory.

Interestingly, even within the Samuelson-sato framework, the theoretical restrictions would not be unattainable if the utility function were weakly separable in the block of goods (see Samuelson and Sato (1984), pp. 592-95). Hence, it is legitimate to impose or test for any of the restrictions implied by theory if one assumes, or, even better, tests fot and (where applicablel imposes blockwise weak separability in goods. The latter was done in this study, since weak separability in the block of goods could not be statistically rejected."

\footnotetext{
${ }^{2}$ Of course, this amounts to suggesting that money is held for the "moneyness" of it. While tautoiogical, this statement can be made operational by hypothesizing that, on the margin, the extent to which income is forgone when monetary assets are held is a measure of the moneyness that these assets possess. The gain that is realized by adopting this hypothesis is considerable; not only does it play a key role in the measurement of the flow of monetary services in terms of readily observable data, it also inherently captures the various degrees of moneyness provided by various monetary assets.

The manner in which weak separability was tested for is dis" cussed at length in Fayyad (1986), chapter 4. A preliminary draft of a paper on this subject is available on request.
} 
rate paid on that asset and the maximum available holding period yield."

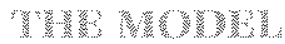

For $n$ goods, the (discrete-time) absolute price version of the Rotterdam model is given by

(1) $w_{i 1}^{*} D x_{i 1}=\mu_{i} D m_{1}^{*}+\sum_{j=1}^{n} \pi_{i j} D p_{i 1}+\varepsilon_{i t} \quad i=1, \ldots, n . .^{*}$

The $x$ 's and $p$ 's denote the quantities and prices of the various goods, respectively, and the subseript $t$ indexes time. $\mathrm{D}$ is the log-change operator; thus $\mathrm{D} \mathrm{x}_{i \mathrm{i}}=$ $\Delta\left(\log x_{i 1}\right), w_{i}$ denotes the expenditure (value) share of the ith good. $w_{i t}^{*}=\left(w_{i, 1-1}+w_{i}\right) / 2$ is that good's average value share over two successive time periods. Thus, the dependent variables in the model are the (average) sharemeighted growth rates of the quantities of goods. The explanatory variables are the growth mates of real income $\left(\mathrm{m}_{1}^{*}\right)$ and prices. "The last term in the system of demand equation $1, \varepsilon$, denotes the demand disturbance. The properties of this term are discussed in appendix $A$ in conjunction with the estimation procedure employed in this study.

The parameters of the model are $\mu_{i}$ and $\pi_{i j}$ $\mu_{\mathrm{i}}\left(=\rho_{\mathrm{i}} \frac{\partial \mathrm{x}_{\mathrm{i}}}{\partial \mathrm{m}}\right)$ is the marginal budget share of the ith good. $\pi_{i \mathrm{i}}\left(=\frac{\mathrm{p}_{\mathrm{i}} \mathrm{p}_{\mathrm{i}}}{\mathrm{m}} \frac{\partial \mathrm{x}_{\mathrm{i}}}{\partial \mathrm{p}_{\mathrm{i}}},(\mathrm{j}=1, \ldots, \mathrm{n})\right)$ is the ith good's price coefficient. Under the standard assumptions of economic theory, if the consumer maximizes a neoclassical utility function subject to a budget constraint, then the above parameters satisfy the following constraints:

(2) $\sum_{\mathbf{i}} \mu_{\mathbf{i}}=1$,

(3) $\sum_{\mathbf{j}} \pi_{\mathrm{ij}}=0$
(4) $1 \pi_{i j}$ is symmetric and negative semidefinite."

In the estimation procedure employed in this study, the constraints $\Sigma \mu_{i}=1, \Sigma_{i j} \pi_{i j}=0$, and $\left\lfloor\pi_{i j}\right\rfloor=\left\{\pi_{i j} \mid\right.$ were imposed. The negative semidefiniteness of the $\left[\pi_{\mathrm{ij}}\right.$, matrix was not imposed; however, it was checked for.

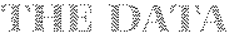

The data consist of U.S. quarterly time series of expenditures on, and prices of food, nondurables. services and two blocks of monetary assets for the period I/1969-1/1985. Together, the two blocks of monetary assets, M1 and ABM1, comprise the 27 assets that the Federal Reserve Board curently recognizes as potential soumces of monetary services in the U.S. economy. M1 is the narrow monetary aggregate, consisting of currency and total checkable deposits. ABM1 consists of the non-M1 monetary assets shown in table 1 .

Data on the first three commodity groups (food, nondurables and services) were obtaned as follows: $A$ time series on the price of each commodity group ( $\left.p_{i}\right)$ was generated from avaiable time series on currentdollar and (1972) constant-dollar consumption expenditures $\left(p_{i \neq} q_{i,}\right.$ and $p_{i, 72} q_{i z}$ respectively) and the identity $\left(p_{i 3} / p_{i, 22}\right)=\left(p_{i 1} q_{i 1} / p_{i, r a} q_{i 1}\right)$. Pel'capita constant dollar expenditures in each quarter were then obtained by dividing the aggregate constant-dollar expenditures by the corresponding mid-quarter population size $\left(N_{1}\right)$. Thus, in terms of the variables which appear in the estimated system, $x_{i 1}=\frac{1}{N_{t}} p_{i t r} q_{i r}$

One can genemate the data on the quantities and prices of MI and ABM1 monetary services as follows:

(1) Convert the nominal balances of monetary assets into real balances by deflating the formes by the "true cost-of-living index." In this study, this index was the geometric mean of the Consumer Price Index and the Commerce Department's implicit

\footnotetext{
"The maximum avaikable holding-period yield is the highest yield of those available either on the monetary assets or on Baa-rated bonds.
}

'A detalled discussion of the model's derivation and applications can be found in Theil $(1971,1975,1976,1980)$, Barten $(1969)$, and Barnett $(1979,1981)$.

In this study, the terms "expenditure" and "income" are used interchangeably. When the latter is used, however, it means "full income." that is, income augmented by expenditure on the monem tary assets that are included in this study. In the estimation procedure employed in this study, $\mathrm{Dm}_{\mathrm{t}}^{*}$ is replaced by $\mathrm{Dx} \mathrm{x}_{\mathrm{t}}$, where $\mathrm{Dx}$, $\sum w_{i t}^{*} D x_{i:}$. See Theil (1971), pp. 331-32
${ }^{9}$ A question may arise as to whether these restrictions are applicable, given that the data are aggregated over both goods and consumers. Insofar as goods are concerned. Hicks' composite commodity theorem can be used, assuming that each of the commodity groups is an elementary good. Resolving the more formidable issue of aggregation over consumers requires using the aggregation results produced by Barnett (1979). In his aggregated-over-consumers absolute price version of the Fotterdam model, Barnett treats the macrocoefficients, $\mu$ and $\pi$, as population versions of weighted average microcoefficients, with the weights proportional to correthe same properties as their micro counterparts, $\mu_{i}$ and $\pi_{i j}$. sponding incomes. He then shows that the macrocoefficients have 
Table 1

\section{Potential Monetary Assets}

\begin{tabular}{|c|c|}
\hline Component & Asset Description \\
\hline 1 & Currency and traveler's checks \\
\hline 2 & Demand deposits held by households \\
\hline 3 & Demand deposits held by business firms \\
\hline 4 & $\begin{array}{l}\text { Other checkable deposits less Super NOW } \\
\text { accounts }\end{array}$ \\
\hline 5 & Super NOW accounts at commercial banks \\
\hline 6 & Super NOW accounts at thrifts \\
\hline 7 & Overnight repurchase agreements \\
\hline 8 & Ovemight Eurodollars \\
\hline 9 & Money markel mutual fund shares \\
\hline 10 & $\begin{array}{l}\text { Money market demand deposit accounts at } \\
\text { commercial banks }\end{array}$ \\
\hline 1 & Money market demand deposit accounts at thrifts \\
\hline 12 & $\begin{array}{l}\text { Savings deposits less MMDAs at commercial } \\
\text { banks }\end{array}$ \\
\hline 13 & $\begin{array}{l}\text { Savings deposits less MMDAs at savings and } \\
\text { loans }\end{array}$ \\
\hline 14 & $\begin{array}{l}\text { Savings deposits less MMOAs at mutual savings } \\
\text { banks }\end{array}$ \\
\hline 15 & Savings deposits less MMDAs at credit unions \\
\hline 16 & $\begin{array}{l}\text { Small time deposits and retal repurchase } \\
\text { agreements at conmercial banks }\end{array}$ \\
\hline 17 & $\begin{array}{l}\text { Small time deposits and retal repurchase } \\
\text { agreements at thrifts }\end{array}$ \\
\hline 18 & Small nime deposits at credit unions \\
\hline 19 & Large time deposits al commercial banks \\
\hline 20 & Large time deposits at thrifts \\
\hline 21 & Instilutional money market mutual funds \\
\hline 22 & $\begin{array}{l}\text { Term repurchase agreements at commercial } \\
\text { banks and thrifts }\end{array}$ \\
\hline 23 & Term Eurodollars \\
\hline 24 & Savings bonds \\
\hline 25 & Shott-term Treasury securities \\
\hline 26 & Banker's acceptances \\
\hline 27 & Commercial paper \\
\hline
\end{tabular}

price deflator for personal consumption expenditures.

(2) Evaluate the real balances of each monetary asset in the base period at its real user-cost price to obtain the real expenditure on that asset during the base period."

(3) Sum the expenditures thus obtained over the components of M1 and ABM1.

(4) Compute the Tornqvist-Theil Divisia quantity in-

\footnotetext{
${ }^{10}$ The user-cost price of money was derived by Barnett (1978). See also Barnett (1986) and (1981), chapter 7.
}

dexes for M1 and ABM1 for the entire sample period.

(5) Set the base-period expenditures obtained in (3) equal to the respective quantity indexes computed in 4 ) and interpolate to acquire complete series on the real expenditures on the monetary services provided by M1 and ABM1.

(6) Construct Tönqvist-Theil Divisia price indexes of the usermcost prices of the respective components of $\mathrm{M} 1$ and $\mathrm{ABM} 1$.

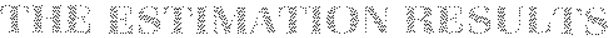

The maximum likelihood estimates of the parame ters of the absolute price version of the Rotterdam model and the associated income and price elasticities are reported in table 2." Estimates of the income coefficients $\left(\mu_{i}\right)$ are all positive and statistically significant at usual significance levels, indicating that the five commodity groups included in this study are normal goods.

The income elasticity of demand for M1 shown in table $2(0.53)$ is similar to those reported in other studies. Moreover, if corresponds closely to its theoretical value of 0.50 implied by the Baumol 1952)Tobin (1956) inventory - theoretic model of the transactions demand for money.

The own- and cross-price coefficients $\left(\pi_{i j}\right)$ are generally estimated with less precision than the income coefficients. Consistent with the standard assumptions of economic theory, estimates of the (Slutsky) own-price coefficients are negative, although not al] are statistically significantly different from zero at usual significance levels. ${ }^{\mathrm{z}}$

\footnotetext{
"The income elasticity of demand for the ith commodity group, $\mu_{i}$ is given by $\mu_{\mathrm{j}}=\frac{\mu_{\mathrm{j}}}{W_{\mathrm{i}}}$. This result can be verified by a simple manipulation of the definition $\mu_{i}=\frac{\partial \mathrm{x}_{i}}{\partial \mathrm{m}}$, On the other hand, the Hicks-Allen price elasticity of demand for the ith group, $\mu_{i_{i}}$, is given by $\mu_{i j}==\frac{\pi_{i j}}{W_{k}}$ which can also be verified by a simple manipulation of the definition

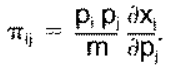

12Negativity of the own-price coefficients, the diagonal elements in the $\left[\pi_{i j}\right]$ matrix, is a necessary, but not sufficient, condition for it to be negative semidefinite; a matrix is negative semidefinite if and only if all of its characteristic roots are nonpositive, and at least one root is zero. This property, which was not imposed in this study, was examined by computing the characteristic roots of the estimates of the $\left[\pi_{i j}\right]$ matrix in table 2. The computed characteristic roots are $(0.0000,0.0000,-0.0022,-0.0097, \cdots 0.1743)$; thus, the negativity condition is satisfied.
} 
Table 2

Maximum Likelihood Estimates of the Absolute Price Version of the Rotterdam Model

\begin{tabular}{|c|c|c|c|c|c|c|}
\hline \multirow{2}{*}{ Equation } & \multirow{2}{*}{$H_{1}$} & \multicolumn{5}{|c|}{$\pi_{i 1}$} \\
\hline & & Food & Nondurables & Services & ABM1 & $M 1$ \\
\hline Food & $\begin{array}{l}0,187083 \\
(6,682878)\end{array}$ & $\begin{array}{r}-0.116241 \\
(-7.380222)\end{array}$ & $\begin{array}{l}0.058199 \\
(4.867328)\end{array}$ & $\begin{array}{l}0057593 \\
(3167629)\end{array}$ & $\begin{array}{l}0.000352 \\
(2913345)\end{array}$ & $\begin{array}{r}0,000097 \\
(1779196)\end{array}$ \\
\hline Nondurables & $\begin{array}{r}0.291246 \\
(9685506)\end{array}$ & $\begin{array}{l}0.058199 \\
(4867328)\end{array}$ & $\begin{array}{r}0034326 \\
(-1918331)\end{array}$ & $\begin{array}{r}0.024572 \\
1228305)\end{array}$ & $\begin{array}{l}0000549 \\
(2129760)\end{array}$ & $\begin{array}{r}0000150 \\
(1319010)\end{array}$ \\
\hline Services: & $(0,467938$ & $\begin{array}{l}0057593 \\
(0.167629)\end{array}$ & $\left(\begin{array}{r}0024572 \\
1228305)\end{array}\right.$ & $\begin{array}{l}-0,034144 \\
-1135707)\end{array}$ & $\begin{array}{c}0,000882 \\
(1596066)\end{array}$ & $(0000242$ \\
\hline ABMI & 0,042172 & $\begin{array}{l}0000352 \\
(2913345)\end{array}$ & $\begin{array}{l}0000549 \\
(2020760)\end{array}$ & $\begin{array}{r}0000082 \\
(1,596066)\end{array}$ & $\begin{array}{r}-0,001399 \\
2058969)\end{array}$ & $\begin{array}{r}0000384 \\
(1,832747)\end{array}$ \\
\hline MI & $\begin{array}{c}0011561 \\
(3.043011)\end{array}$ & $\begin{array}{c}0000097 \\
(1779196)\end{array}$ & 0000150 & $(0,600242$ & $\begin{array}{r}0.000384 \\
(-1832747)\end{array}$ & $\begin{array}{r}0000105 \\
0.276950)\end{array}$ \\
\hline
\end{tabular}

Note tratos are in parentheses:

Average Income Elasticities

0.828044

Nondurables

1.390072
Services

0.942341
ABM

1.027321
M1

0.525813
Average Hicks Allen Elasticltes

\begin{tabular}{|c|c|}
\hline & Food \\
\hline Food & 0.514493 \\
\hline Nondurables & 0.277775 \\
\hline Services 2 & 0115982 \\
\hline$A B M 1$ & 0,008585 \\
\hline & 00004394 \\
\hline
\end{tabular}

$$
\begin{aligned}
& \text { Nondurables } \\
& 0,257394 \\
& 0,163834 \\
& 0.049483 \\
& 0,013365 \\
& 0,006841
\end{aligned}
$$

$$
\begin{array}{r}
\text { Servces } \\
0254911 \\
0117278 \\
0068760 \\
0021474 \\
0010991
\end{array}
$$

ABM1
0001560
0002619
0001775
00034071
0017464

Mt

0,000428

0.000718

0.000487

0.009354

0004763

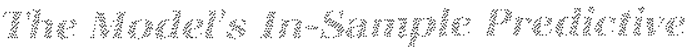

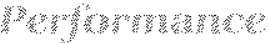

As stated earlier, the Rotterdam model can be used to provide predictions of the value (budget) shares. The model's implied prediction of the share of the ith good at time $t$ is given by

$$
\hat{\mathrm{w}}_{\mathrm{i}, t+3}=\mathrm{w}_{\mathrm{il}}-\mathrm{e}_{\mathrm{it}},
$$

where $w_{i 1}$ is the actual value share of the ith good, and $e_{\mathrm{i}}$ is the residual of the ith demand equation at time $t$.

The in-sample predictive performance of the Rotterdam model can be evaluated in terms of its information-theory results; a general discussion of this method of assessing prediction accuracy is presented in appendix B. Computed measures of information (prediction) inaccuracies from the model are reported in table 3 , along with information-inaccuracy measures for a nave (no-change) extrapolation of the value shares. The reported measures show substantial reductions in information inaccuracies when the model results are compared with the naive predictions. ${ }^{13}$

Further insight into the model's in-sample predictions may be gained by plotting the actual and predicted shares; this is done in charts $1-5$. An inspection of these charts reveals that the model's in-sample predictions track the dafa extremely well; this is especially true for the M1 equation despite considerable variability in the actual shares of M1. These results suggest that the demand for M1, as derived in this

\footnotetext{
13in fact, in view of the greater variability of the shares of $M 1$ and ABM1 reataive to the shares of the other goods and services shown in charts $1-5$, it is not surprising that predictions from the money equations "beat" the nave model by a larger margin than predictions from the other equations. In the presence of high period-toperiod variation in the actual shares, the no-change nave model wit always perform poorly.
} 
Table 3

Average Information Inaccuracies'

\begin{tabular}{|c|c|c|}
\hline & Rotterdam Model & Naive \\
\hline \multicolumn{3}{|l|}{ System Results } \\
\hline Uncorfected information inaccuracy & 14.40 & 45260 \\
\hline Information inaceurac y with of correction & 14.82 & \\
\hline Percent reduction from naive & $9673 \%$ & \\
\hline \multicolumn{3}{|l|}{ Single Equation Results } \\
\hline Food nformation inaccuracy & 3.505 & 12.18 \\
\hline Percent reduction rom nave $\mathrm{a}$ & $7122 \%$ & \\
\hline Nondurables intomation nacouracy & 4141 & 1195 \\
\hline Percentreducton from nave & $6535 \%$ & \\
\hline Services information inaccuracy & 5943 & 3454 \\
\hline Percent reduction trom nave & $8279 \%$ & \\
\hline ABM1 inoination naccuracy & 5083 & 381,30 \\
\hline Percent reduction from nave & $9867 \%$ & \\
\hline Mitormation naccuracy & 0.646 & 51,30 \\
\hline Percentreduction from nave & $9874 \%$ & \\
\hline
\end{tabular}

The niomation naccuractes are to be nuttiplied by 10 .

\section{Chast 1}

\section{Actual vs. Predicted Value Shares of Food}

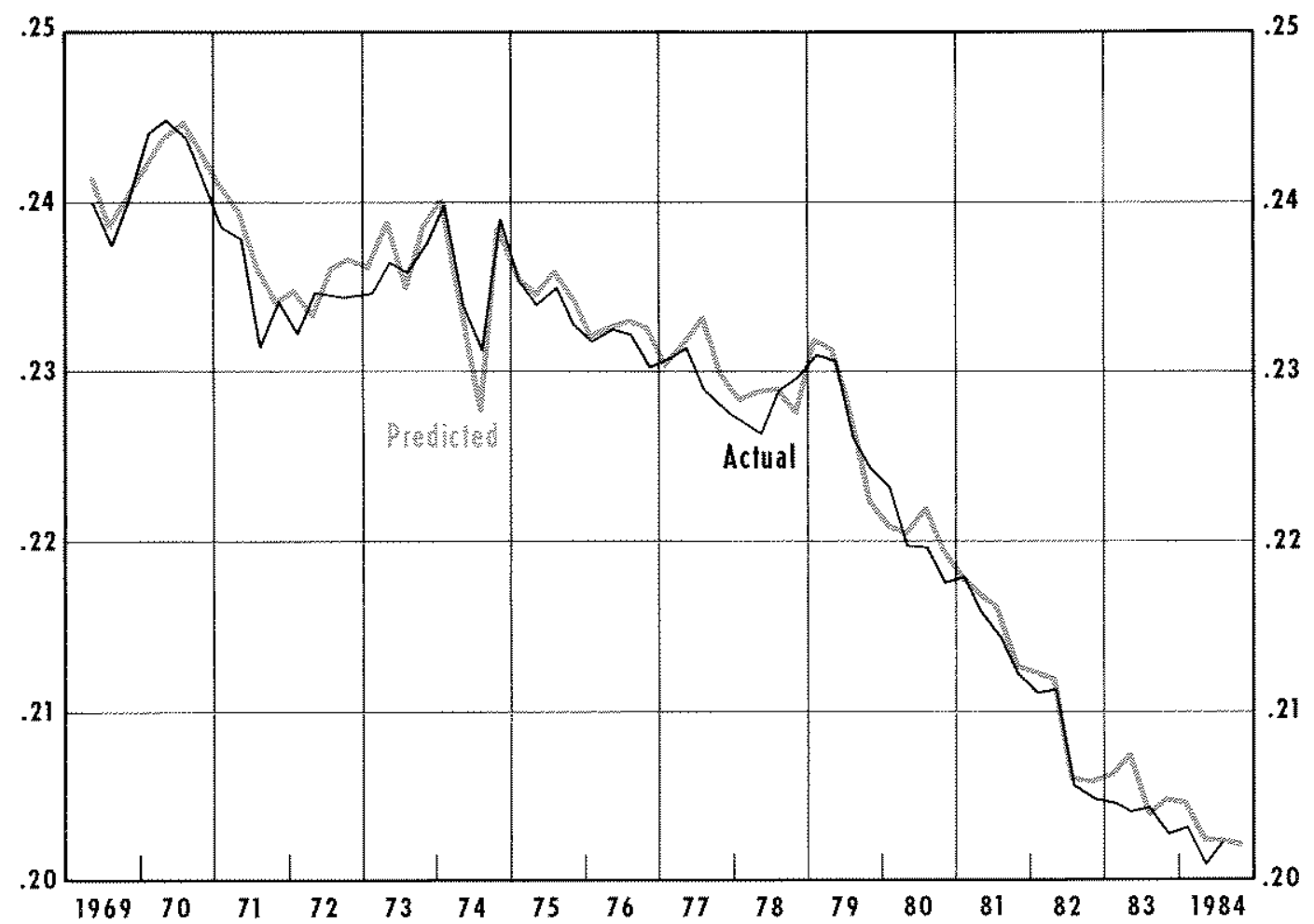




\section{Chart 2}

Actual vs. Predicted Value Shares of Nondurables

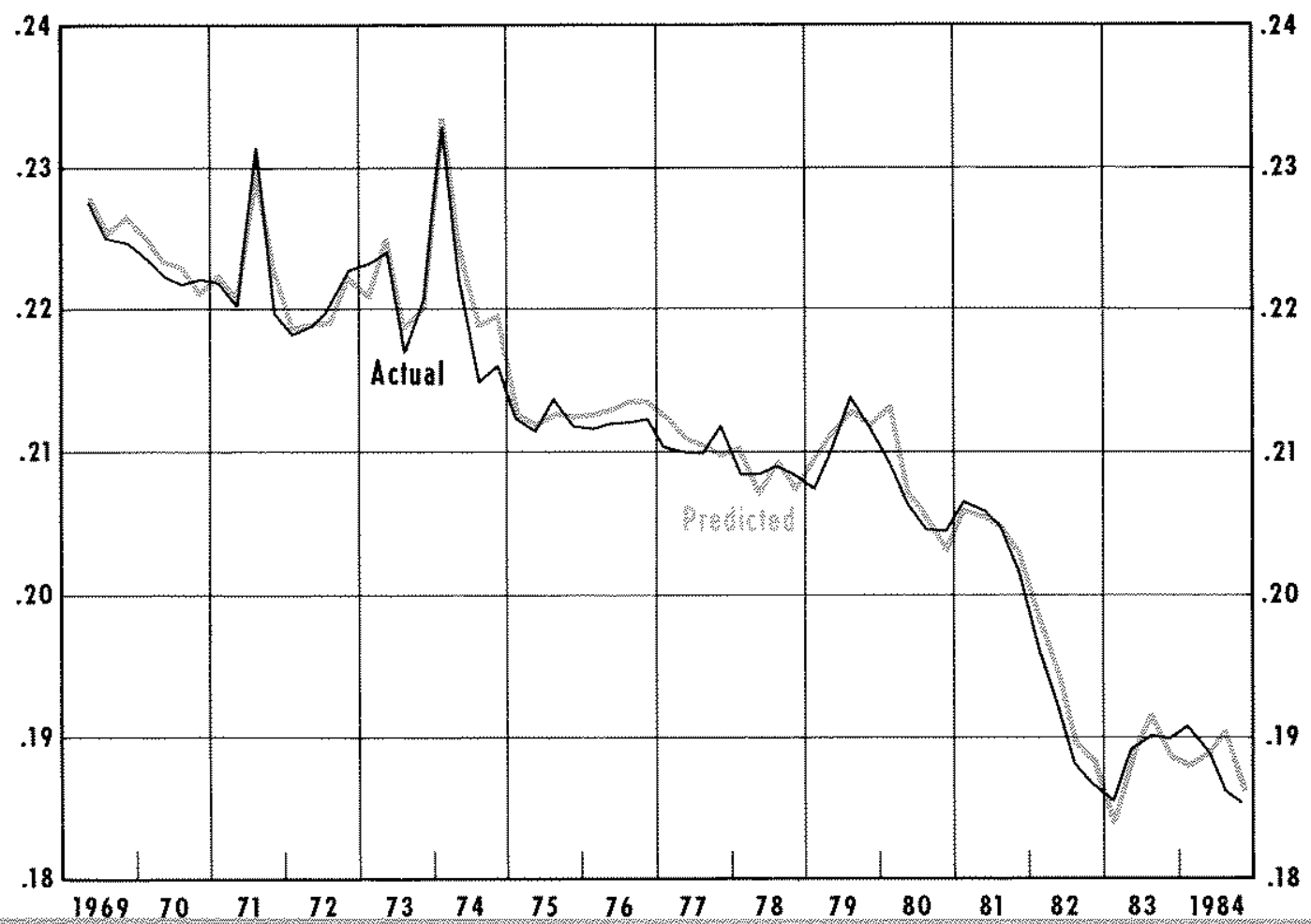
Chart 3

Actual vs. Predicted Value Shares of Services

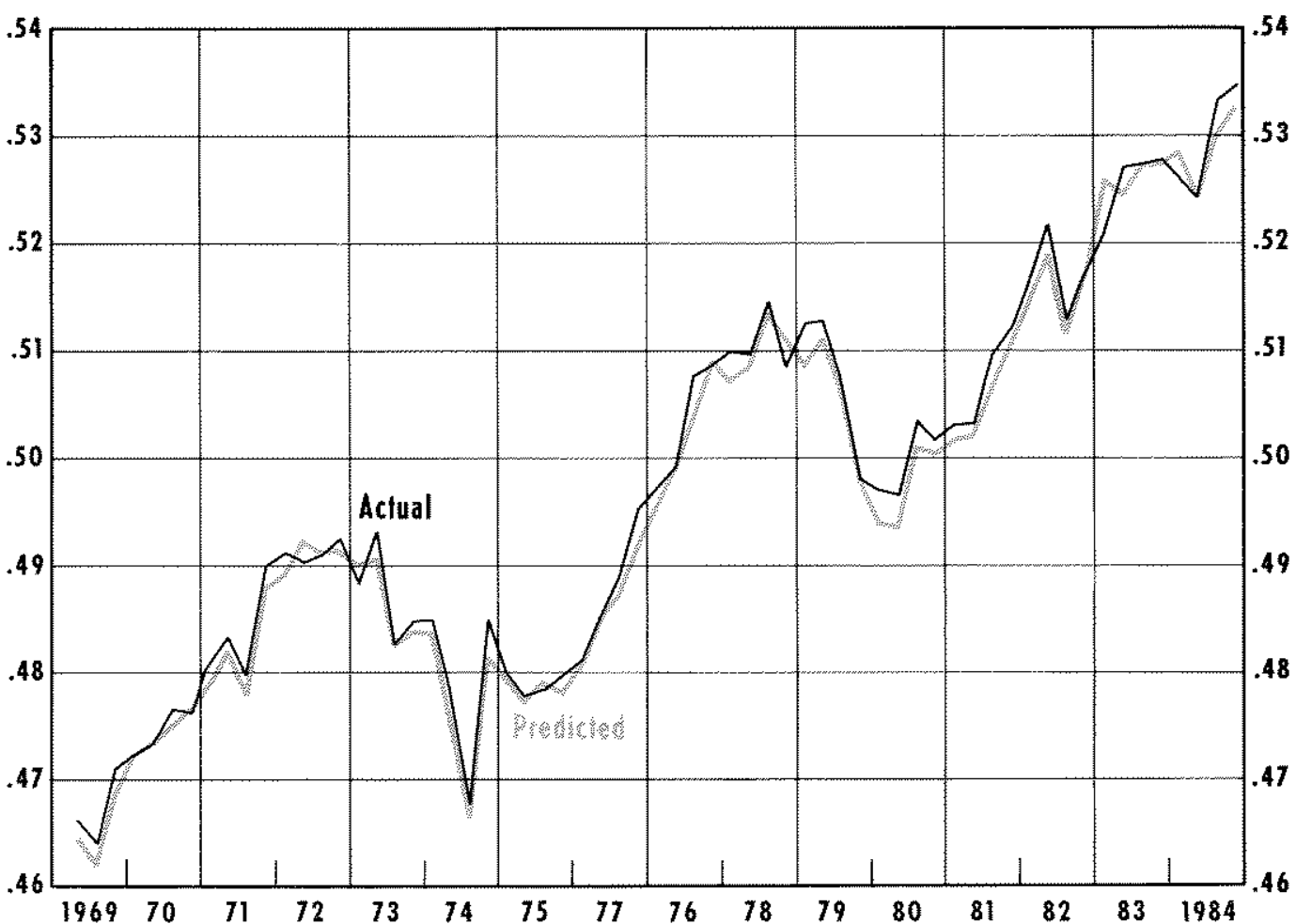


Chat 4

Actual vs. Predicted Value Shares of ABMI

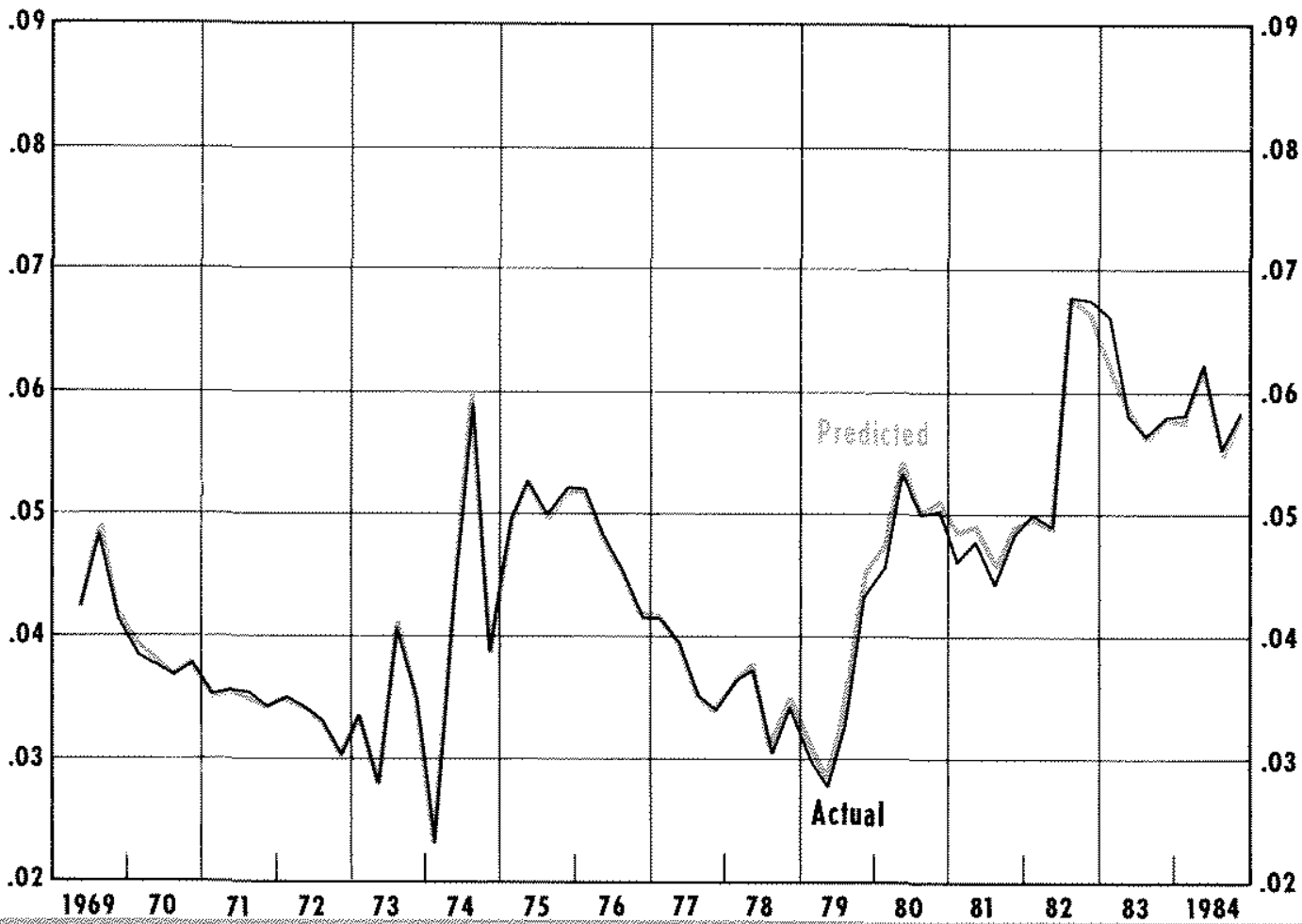

Char 5

Actual vs. Predicted Value Shares of MI

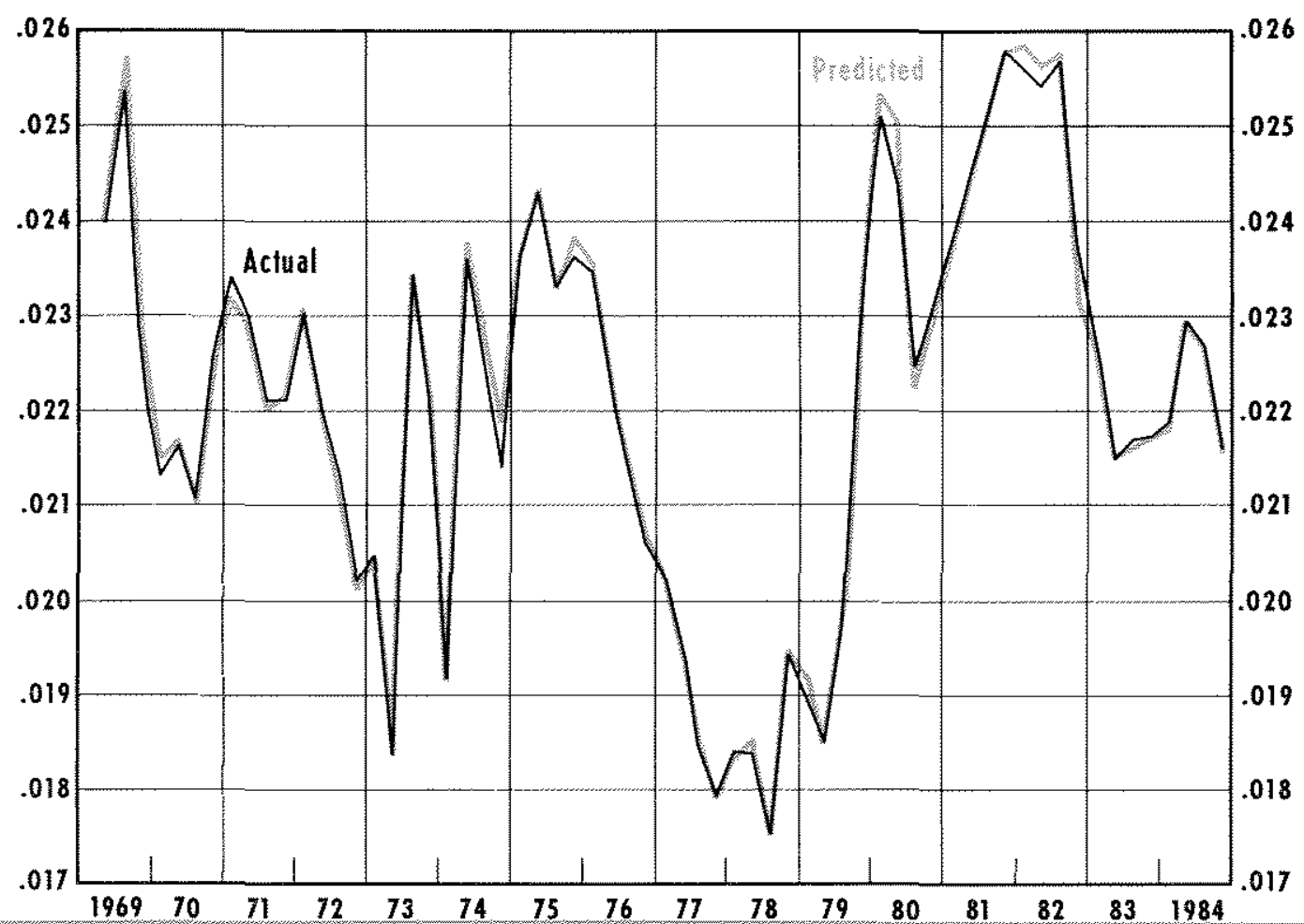


study, was more stable than the demand for other goods, services and financial assets over the sample period.

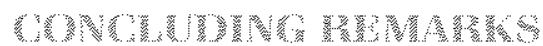

This study has discussed an approach to the estimation of the demand for money that relies on a methodology markedly different from that emploved in the conventional money demand analysis. The approach is explicitly derived from the principles of micoeconomic theory and emphasizes the importance of interaction among goods. The modeling process is not influenced by a seach for "goodness of fit"; instead the emphasis is placed on the model's consistency with explicit utility-maximizing conditions.

The empirical results produced in this study show that it is possible to specify a model of money demand that closely tracks the actual behavior of the flow of MI's monetary services despite its considerable variability over this period. Thus, there seems to be nothing mysterious about that variability; it can be explained in terms of changes in relevant economic variables. These results indicate that money demand has been considerably more stable over the past two decades than standard money demand analysis has suggested.

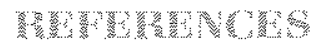

Bamett, Witliam A. "The User Cost of Money," Economics Letters, Vol. 1 (1978), pp. 145-49.

"Theoreticat Foundations for the Rotterdam Model," Review of Economic Studies, Vot. 46 (1979), pp. $109-30$.

Amsterdam, 1981 ). and Kenneth Singieton. "The Microeconomic Theory of Monetary Aggregation," New Approaches to Monetary Economics (Cambridge University Press, forthcoming).

Barten, A. P. "Maximum Likelihood Estimation of a Complete Demand System," European Economic Review, Vol. 1 (1969), pp. 7 73.

Baumol, Wiltiam J. "The Transactions Demand for Cash: An Inventory Theoretic Approach," Quarterly Joumal of Economics (November 1952). pp. 545-56

Ewis, Nabil A. and Douglas Fisher. "The Translog Utility Function and the Demand for Money in the United States," Joumal of Money, Credit, and Banking (February 1984), pp. 34-52.

Fayyad, Salam K. "Monetary Asset Component Grouping and Aggregation: An Inquiry into the Definition of Money" (Ph.D. dissertation, The University of Texas at Austin, 1986).

Goldfeld, Stephen M. "The Demand for Money Revisited," Brookings Papers on Economic Activity (3:1973), pp. 577-646.

"The Case of the Missing Money," Brookings Papers on Economic Activity (3:1976), pp. 683-739.

Judd, John P. and John L. Scadding. "The Search for a Stable Money Dernand Function: A Survey of the Posi-1973 Literature," Joumal of Economic Literature, Vol. 20 (1982), pp. 993-1023.

Mizrach, Bruce and Anthony M. Santomero. "The Stability of Mtoney Demand and Forecasting through Changes in Regimes," The Review of Economics and Statisfics (May 1986), pp. 324-28.

Samuelson, Paul A. Foundations of Economic Analysis (Harvard University Press, 1983).

and Ryuzo Sato. "Unattainability of Integrability and Definiteness Conditions in the General Case of Demand for Money and Goods," American Economic Review (September 1984), pp. $588-604$.

Theil, Henri. Economics and Information Theory (North-Holland, Amsterdam, 1967).

Principles of Econometrics (Wiley, 1971).

Theory and Measurement of Consumer Demand, Vol 1 (North-Holland, Amsterdam, 1975).

Theory and Measurement of Consumer Demand, Vol. 2 (North-Holland, Amsterdam, 1976).

The System-Wide Approach to Microeconomics (University of Chicago Press, 1980).

Tobin, James. "The Interest Elasticity of Transactions Demand lor Cash," Review of Economics and Statistics (August 1956), pp. $241-47$.

(See appendixes $A$ and $B$ on following pases) 


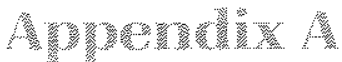

In order to estimate the functional form of the demand equations, a stochastic version of that form should be specified and the disturbanee terms interpreted. The system of demand equations can be written as follows,

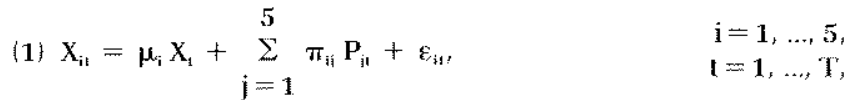

where $\left.X_{i 1}:=w_{i 1}^{*} D x_{i t}\right)$ is a $T$-dimensional vector of observations on the left-hand-side variables of the ith commodity group, $p_{i f}=D p_{i l}$ is a $T$-dimensional vector of the log-change in the price of the ith commodity group, $\mu_{i}$ is the marginal budget share of the ith commodity group $\left./ \pi_{\text {if }}\right)$ is a $5 \times 5$ 5 matrix of the price coefficients, and $x_{t}\left(=\sum_{i=1}^{\infty} w_{i 2}^{*} b x_{i t}\right)$ is a T-dimensional vector of the (budget-share) weighted sum of the log-change in expenditures on the five commodity groups.

The last term in equation $1, \varepsilon_{11}$, is the disturbance term of the themand equation. The disturbance terms, $\left[\varepsilon_{i 1}\right]$, are assumed to caplure the random effects of all variables other than income and all prices. The distubance terms are further assumed to be nomally distributed with mean zero and a variance-covariance matrix $\Sigma \otimes l_{\mathrm{F}}$, such that

(2) $E\left(\varepsilon_{\mathrm{k},}, \varepsilon_{\mathrm{i}}\right)=\sigma_{\mathrm{ij}}$

for $s=\mathbf{t}$

(3) aind $\mathrm{E}\left(\varepsilon_{\mathrm{ix},}, \varepsilon_{\mathrm{ij}}\right)=0$

$\mathrm{fol}^{2} \mathrm{~s} \neq \mathrm{t}$

where $\otimes$ is the Kronecker product, $I_{T}$ is a $T \times T$ identily mati $i x$ and $\sigma_{i i}$ is the $i$, jth element of the $5 \times 5$ matrix, $\Sigma$.

Another property of the demand-disturbance terms is that their sum vanishes with unil probability isee Barten (1969), p. 16 and Theil $(1971)$, p. 333). A potentially tretiblesome implication of this property is that

$$
\sum \sigma_{i j}=E\left(\varepsilon_{i t}\left(\varepsilon_{1 \mathrm{t}}+\ldots+\varepsilon_{i+1}\right)=0 .\right.
$$

'Thus, the covariance matrix, $\Sigma$, is singular, and as such, cannot have a mank that is lager than $n-1$. In what follows, it is assumed that the rank of $\Sigma$ is exactly $n-1$. In order to circumvent the complications posed by this singularity problem, one equation of the system $\{1\}$ is deleted. The legitimacy of this procedure can be verified easily by summing over $i$ any four of the five equations of the system and using the properties of that system in order to recover the deleted equation. In fact, a major arvantage of the estimation method used in this study, full information maximum likelihood (FIML), is that the parameter estimates it produces are invariant to the equation deleted isee Barten (1969), pp. 25-27).

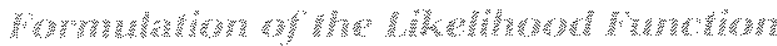

For notational convenience, the system of demand equations (1) may be written as follows,

(4) $\left.y_{1}=g \mid x_{1}, \theta\right)+\varepsilon_{1}$,

where $y$, are the vectors of the left-hand-side variables of (1), $x_{4}$ are the vectors of the right-hand-side variables, $\varepsilon_{1}$ are the vectors of the demand-disturbance terms, and $\theta$ is the vector of the parameters $\mu_{i}$ and $\pi_{i i}$. Since the additive disturbance vectors $\varepsilon_{1}=\left(\varepsilon_{7}, \ldots, \varepsilon_{31}\right), t=1, \ldots, T$, are assumed to be independently nomally distributed with mean 0 and variance-covariance matrix $\Sigma$, it follows that the vectors $y_{\text {, }}$ must also be independently normally distributed with mean $g\left(x_{1}, \theta\right)$ and variance-covariance matrix $\Sigma$. In arriving at the vector-valued function $g$, it is assumed for notational convenience that prior restriction on the parameters has already been eliminated by substitution.

Given the observed data on $y=\left(y_{1}, \ldots, y_{r}\right)$ and $x=\left(x_{1}, \ldots, x_{v}\right)$ the $\log$-likelihood function on $\Theta$ and $\Sigma$ is given by

$$
\begin{aligned}
& \text { (5) } \mathrm{L} .(\Theta, \Sigma ; y, x)=-(1(n-1) / 2) \log 2 \pi|\Sigma|
\end{aligned}
$$

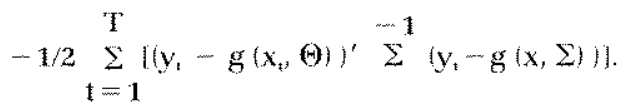

This function is to be maximized with respect to the elements of the parameter vector $\theta$ and the elements of the variance-covariance matrix, $\Sigma$. For computational convenience, however, and since the asymptotic distribution of $\Sigma$ is not at all needed, a stepwise-optimation procedure is used. This procedure involves first maximizing the loglikelihood function (5) with respect to the elements of $\Sigma$, for a given value of $\Theta$, to obtain an expression for $\Sigma$ in 1 terms of the elements of $\theta$. Thus, for $\theta=\Theta^{*}$, the value of $\Sigma$ that maximizes $(5)$ is given by

(6) $\Sigma^{*}\left(\Theta^{*} ; y, x\right)=\frac{1}{T} \sum_{t=1}^{T}\left(y, \cdots, g\left(x_{3}, \theta\right) \| y, \cdots, g\left(x_{1}, \theta\right)\right)^{\prime}$

Substitution of $2^{*}$ into $(5)$ yields

(7) $L(\theta ; y, x)=-[T(n-1) / 2) \log 2 \pi|\operatorname{Li}(\theta ; y, x)| \frac{1}{2}(\operatorname{Tn}-1)$,

which is the concentrated likelhood function.

The second step in the optimization procedure becomes immediately clear when one recognizes fhat maximizing the $\log$-likelihood function $(5)$ is equivalent to minimizing the deterninant of $\sum$ in (7). The latter is accomplistued by searching the feasible parameter space for the value of $\theta$ at which $|\mathrm{z}|$ is minimized. The values of the elements of $\theta$ thus obtaned, $\hat{\theta}$, are the maximum likelhood estimates of 
the system (1). The asymptotic covariance matrix of $\hat{\theta}$ is obtained by inverting the matrix $-1 \frac{\partial^{2} L}{L}$, which is numeri$\partial \Theta \partial \Theta^{\prime}$

cally evaluated at $\Theta=\hat{\theta}$. Naturally, the elements of that matrix pertain only to the estimated parameters. The as ymptotic covariance matrix of the entite vector of (estimated as well as computed parameter estimates is derived in Fayyad $(1986)$

\section{Apmendix}

Available results from information theory can be used to develop measures by which the perfomance of each of the estimated equations as well as that of the system as a whole can be gauged. Consider an infhitesimal change in the budget share of the ith commodity $\left(w_{i}=p_{i} x_{i} /\right.$ rin:

$$
d w_{i}=\frac{x_{i}}{m} d p_{i}+\frac{p_{i}}{m} d x_{i}-\frac{p_{i} x_{i}}{m m^{2}} d m
$$

from which it follows that

(1) $d w_{i}=w_{i} d \log p_{i}+w_{i} d \log x_{i}-w_{i} d \log m$.

The finite-change analog of equation 1 is given by

(2) $\Delta w_{i 1}=w_{i 1}^{*} D p_{i 1}+w_{i 1}^{*} D x_{i 1}--w_{i 1}^{*} D m_{1}$.

Since $\mathrm{Dm},=D x_{1}+D p_{1:}$ it follows that equation 2 can be rewritten as

(3) $\Delta w_{i 1}=w_{i 1}^{*} D x_{1 !}+w_{i 1}^{*}\left(D p_{i 1}-D p_{1}\right)-w_{i}^{*} D x_{1}$.

Observe that the fitst term on the righthand-side of equa tion 3 , to be interpreted as the quantity component of the change in the budget share of the ith good, is the dependent variable of the ith demand equation of the estimates system. Thus, given the log-changes in reat income and relative prices, the Rotterdam model can be lsed to provide conditional forecasts of $w_{i k}^{*} D x_{i}$ and, through equation 3 of $\Delta w_{i 1}$. Since the prediction of $w_{i 1}^{*} D x_{i 1}$ is equat to the right-handside of the ith demand equation with the distubbance tem deleted, it follows that

$$
\hat{w}_{1,1+1}=w_{\mathrm{t}_{1}}-e_{\mathrm{i} 1}
$$

where $\hat{w}_{i, 4+1}$ is the implied prediction of $w_{1,}$, and $e_{1,}$ is the residual of the ith demand equation in period $t$.

In view of the fact that the budget shares are positive and add up to unity, they may be viewed as probabilities. A measure of the model fit can be acquired by determining the expected gain in information from the actual shares, which can be viewed as posterior probabilities, when the

'See Theil (1967), pp. 1-48; (1971), pp. 646-50, and Barnett (1981), pp. $149-54$. implied predictions tor the fitted values of these shates are viewed as prior probabilities. That measure is given by

(4) $\mathrm{L}_{\mathrm{i}}=\sum_{\mathrm{i}=1}^{\mathrm{n}} \mathrm{w}_{\mathrm{i}} \log \frac{\mathrm{w}_{\mathrm{i} t}}{\mathrm{w}_{\mathrm{i} t}}$,

where $l_{2}$ is the information inaccuracy of the predictions provided by the system of demand equations. It is to be noted that not only is this measure of infomation inacaracy additive over goods, as is indicated by the expression in (4), but it is also additive over time. Thus, it is possible to construct an average index of information maccuracy, $\bar{T}$, over the period from $l_{7}$ to $l_{2}$ by using the following formula

15) $\overline{\mathrm{I}}=\frac{1}{\mathrm{t}_{z}-\mathrm{t}_{\mathrm{k}}+\mathrm{t}} \sum_{\mathrm{t}=\mathrm{t}_{\mathrm{t}}}^{\mathrm{t}_{z}} \mathrm{l}_{1}$.

Observe that the information-inaccuracy measures prem sented above pertain to the predictions which are provided by the system of demand equations as a whole. It is possible to aequire a single-equation meastae of information inaccuracy by using the formula

(6) $I_{i 1}=w_{i 1} \log \frac{w_{i 8}}{w_{i 8}}+\left(1-w_{i 1}\right) \log \frac{1-w_{i 1}}{1-\hat{w}_{i 1}}$.

where $1-w_{18}$ is the combined budget share of all commodities other than the ith. As before, the average (over time) index of a single equation information inaccuracy can be obtained by using formula 5 .

In order to provide comparabiaty of the information inaccuracy across models, a correction (adjustment factor should be appled to these measures isee Theil $\{1971\}$ pp. 651-52, and Barnett (1981), p. 150), Adjustment was achieved in this study by multiplying the information-inat curacy measure in each case by a factor of $\mathrm{ML},(\mathrm{ML}-\mathrm{K})$, where $M$ is the number of jomtly estimated equations, $L$ is the number of time periods qquarters, and $K$ is the rumber of unrestricted parameless. Clearly, this procediure is closely akin to the degrees-of-freedom adjustment of the comelation coefficient. 